\title{
Improvement of the Voltage Quality in an Electrical Network via the Loopback: Case of the Southern Interconnected Grid (SIG) of Cameroon
}

\author{
Raissa Onanena $^{1 *}$, Roger Tchuidjan${ }^{1}$, Frederic Biya Motto ${ }^{2}$, Manuella Mamche Gatchessi ${ }^{1}$ \\ ${ }^{1}$ Department of Electrical and Telecommunications Engineering, National Advanced School of Engineering, \\ University of Yaoundé I, Yaoundé, Cameroon \\ ${ }^{2}$ Department of Physics, Faculty of Science, University of Yaoundé I, Yaoundé, Cameroon \\ Email: ^raissa.onanena@polytechnique.cm, tchuir@gmail.com, biyamotto@yahoo.fr, manugatchessi@gmail.com
}

How to cite this paper: Onanena, R., Tchuidjan, R., Motto, F.B. and Gatchessi, M.M. (2021) Improvement of the Voltage Quality in an Electrical Network via the Loopback: Case of the Southern Interconnected Grid (SIG) of Cameroon. Journal of Power and Energy Engineering, 9, 25-41. https://doi.org/10.4236/jpee.2021.93002

Received: December 15, 2020

Accepted: March 28, 2021

Published: March 31, 2021

Copyright $\odot 2021$ by author(s) and Scientific Research Publishing Inc. This work is licensed under the Creative Commons Attribution International License (CC BY 4.0).

http://creativecommons.org/licenses/by/4.0/

\begin{abstract}
Electricity being a basic national infrastructure for a country, its security, reliability and quality are the most important parameters for the network managers. Several methods are generally used to improve the voltage quality more and more. However, most of the means implemented depend on external factors independent of the network managers or require huge regular financial resources. The method used in this paper is the loopback, applied to the Southern Interconnected Grid (SIG) of Cameroon, which is the largest network in the country. The procedure used takes into account nodes experiencing huge voltage drops and network constraints. The chosen loopback scenario results in a clear improvement of the voltage plan in this network, and also a discharge of the transformers, a considerable decongestion of the lines, a reduction of the power losses and a significant reduction of the thermal placement used for improvement of the voltage profile.
\end{abstract}

\section{Keywords}

Electrical Network, Looping, the Southern Interconnected Grid (SIG) of Cameroon, Voltage Quality

\section{Introduction}

The power industry is a basic national infrastructure for a country. Its security, its reliability and its quality have enormous and far reaching effects on a national economy. Questions such as how to improve the operating performances are al- 
ways at the forefront of electrical power system research [1]. In the context of developing countries, two additional constraints are to be considered: financial restrictions and the age of the network. It is in this framework that this paper studies how to improve the voltage level in a power grid, in particular the biggest network of Cameroon. This comes down to power quality. On the principle of the electromagnetic compatibility, it is possible to link the "power quality" with power supply reliability, service quality and supply quality. Usually, in this context, it has been sufficient to distinguish between "voltage quality" and "continuity of supply", which are both important notions [2] [3] [4].

Voltage quality (internationally used term "power quality" (PQ)) is concerned with the technical characteristics of the electricity at a given point of an electrical system, evaluated against a set of reference parameters [2] [5]. In these terms, the deviation of the voltage from the ideal are analysed, considering sine voltage wave of constant amplitude and frequency.

The continuity of supply concerns the probability of satisfactory operation of a system over the long term. In other words, it denotes the ability to supply adequate electrical service on a nearly continuous basis with few interruptions over an extended period of time [2].

Given the definitions above, it can be said that improving the power quality of a network can be done by improving the voltage quality, and thus this could also lead to the continuity of supply. And when there are financial constraints as well as an ageing network that must be taken into account, it is crucial to provide to the System Operator simple and cost-effective solutions.

This paper presents a strategy of improving voltage levels and quality in the electrical network, using the loopback. This procedure takes into account technico-economic aspects in order to determine the appropriate transmission lines for an optimal looping of the network. Our purpose is to not only demonstrate that this strategy could improve the overall voltage plan of the network, but also that it can also allow the discharge of power and a strong decongestion of the transmission lines: this can be interesting in the case of an electrical grid where the economic constraints are particularly high.

The rest of the paper is organized as follows: related works on reducing voltage drops are presented in Section 2; the methodology adopted in this work is given in Section 3; then, the implementation of the steps in the Southern Interconnected Grid (SIG) of Cameroon is done in Section 4; finally, Section 5 concludes the paper.

\section{Literature Review}

This section presents a review of several methods that have been proposed in order to improve the voltage quality in a network.

First, the local production, also called distributed generation can be used to improve the voltage levels in the source substations. Indeed, the connection of decentralised mini-power plants is a very suitable method to limit the power 
transmission in the lines by producing electricity closer to the point of use. In addition to voltage drop reduction and power losses reduction due to the proximity of load and generation, distributed generation can provide advantages such as voltage profile improvement thus PQ improvement, considerable reduction of fossil fuel consumption, power system reliability enhancement, the possibility to use DG units as power back-up in case of a temporary failure of the main power system and long-term deferral of investment in transmission system expansion. However, in the case of the use large DG units, there could be several shortcomings and negative impacts on voltage control, frequency control, and protection system settings. This could lead to difficulty for the implementation, especially if there are also financial constraints [6]-[11].

Another method is the use of capacitor banks, which are devices that generate reactive power to the network from the node to which they are connected. The shunt capacitor banks used to eliminate undervoltages by supplying reactive power [12] [13], as well as shunt reactors used to remedy the overvoltages by absorbing reactive power [12] [14]. This solution also reduces power losses in the network. The goal is to compensate the amount of reactive power absorbed by the power grid and by the high-voltage/medium-voltage (HV/MV) transformers. The main advantage of capacitor banks is the immediate improvement of voltage levels. But this method is a static compensation.

The use of on-load tap changer transformers is possible in order to reduce the voltage drops in the network. They make it possible to adjust the voltage level of the medium-voltage busbars, depending on the evolution of the loads and the fluctuations of the upstream voltage. This is accomplished by adjusting the transformers turn ratio while it is supplying its load. The disadvantages of mechanical tap-changers include long tap-changing time and high maintenance requirements that lead to their use only for steady-state voltage control of power systems [15].

In [16] [17], the Flexible AC Transmission Systems (FACTS) are proposed. The basic control principle of FACTS is that the impedances of a power system can be changed by suitable FACTS controls. Then the power flows and voltages of the power system can be controlled. In addition to the power flow and voltage control capabilities, FACTS can also be used to control voltage stability, dynamic stability or small signal stability, and transient stability or angular stability The main difficulties that are faced when opting for FACTS is the diversity of FACTS and the difficulty to choose where to insert them.

In recent years, in order to provide a solution to the problem of the increasing load, a large number of renewable-energy-based DG have already been integrated in distribution networks [18] [19]. For the mitigation of the additional power quality issues associated with renewable-energy-related DG, various strategies exist. For instance we can cite the conventional methods mentioned above (capacitor banks, on-load tap changer transformers, etc.) [18] [20] [21], reactive power compensation techniques [21] [22] [23], power factor control in 
photovoltaic systems [24] and scheduling and optimisation algorithms [23], [25]. The low level of penetration of renewable energies in the Cameroonian electric power system makes it difficult to implement solutions that use renewable-energies-based DG in this context.

In the present work, the strategy of looping the network is used to improve the voltage levels in an electrical network in order to increase its performances. The main advantages that can be presented are 1) looping is easy to implement in the context of an economically-constrained grid, 2) the facility to choose where to implement the loop and 3) does not require greedy optimization algorithms.

\section{Methodology}

This work is done in normal operating mode, so the transient regime is not taken into account. The looping studied in this article consists of connecting two or more nodes of an electrical network so that an additional line feeds each of them. This allows the grid to provide a continuity of supply in the case of the unavailability of a line at the looped node. Looping a network is usually employed in order to optimize the power transit so that its reliability could be guaranteed; moreover, its exploitation and its maintenance could be facilitated.

However, to implement a looping, there are some constraints that need to be considered such as environmental constraints, financial constraints and mostly technical constraints. From a technical point of view, there are four essential conditions for the looping of an electrical network:

- The two connected busbars must have the same voltage;

- The match of the phases must be respected;

- The frequency of the network must be controlled;

- The choice of conductors must be made optimally.

When two nodes have different voltages, it is necessary to integrate a power transformer during the construction of the line. The looping procedure thus adopted is as follows:

Step 1: Simulations of the base cases.

Step 2: Choice of the looping nodes.

Step 3: Choice of the looping lines.

Step 4: Simulation of the final scenario.

\subsection{Simulations of the Base Cases}

This first step consists of breaking up the considered network into electrical regions, then its load profile into similar periods over the entire year. Subsequently, the simulations of these base cases are carried out according to the different periods of the load profile and the results of the voltages at the different busbars are noted; the period corresponding to the greatest number of unfavorable cases will be retained for the next step. Note also that the looping will be done by region. 


\subsection{Choice of the Looping Nodes}

After choosing the appropriate period, techno-economic criteria are used to determine the nodes to which an optimal looping for each region can be obtained. The criteria used in this study are:

- The lengths of transmission lines: as they increase, the cost of constructing the line increases.

- The voltage levels: the node selected to raise the voltage in a region must itself have the appropriate and stable voltage level permanently.

- The availability of the substation: it corresponds to an operating state for the substation even in case of loss of an electricity transmission facility.

\subsection{Choice of Looping Lines}

After selecting the nodes to which the loopback will be made to the low voltage busbars, a second technico-economic study is carried out, based on the same criteria, of each possible case; then, the most appropriate choice for each region is adopted.

\subsection{Simulation of the Final Scenarios}

In this last step, the network is simulated including all the chosen looping scenarios; subsequently, it is verified that the loopback does not create overvoltages during the other periods of the load profile.

To carry out this study, the Newton-Raphson method has been adopted and implemented here through the PowerWorld Simulator software that is a large-scale electrical network simulation software, performing the load flow studies in these networks. This software takes as input the rated bus bar voltages, the operating voltages at the generating nodes ("PV" nodes), the parameters of lines and transformers, the powers of generators, the rated values of capacitor banks and loads at the different nodes. After simulation, it gives information on the actual voltages at the bus bars, the power flows in the lines, the total power losses or those in lines, etc. PowerWorld Simulator is particularly adapted because of its capacity to simulate and analyze large interconnected grids on large time frames [26].

\section{Results and Comments}

\subsection{Simulations of the Base Cases}

- Segmentation of the network: the SIG of Cameroon can be divided into three electrical regions:

- The Coastal Corridor

- The Central Corridor

- The Western Corridor

- Segmentation of the SIG load profile: The SIG load profile, shown in Figure 1, is subdivided into three periods over a day, with a similar behavior throughout 
a whole year:

- The off-peak period

- The full period

- The peak period.

- Simulation and results

To better study the impact of looping an electrical network, the base cases were selected at periods when the voltage plan is severely degraded despite the implementation of means used in the SIG for improvement, for which we principally have local energy production, insertion of capacitor banks and the use of on-load tap changing transformers. With the simulations performed for the three periods, it is possible to obtain the voltage drops on each node of the grid. Since the most important voltage drops are recorded during the peak period, the rest of the study will be based on data from this period. In general, several thermal power plants are deployed during the peak period, which does not only satisfy the energy demand, but also raises the voltage plan over the entire network. Nevertheless, since some voltage drops remain higher than $10 \%$, which is the average acceptable high voltage limit according to the EN50160 standard [27], this study will put more emphasis on the nodes concerned, grouped in Table 1. More details on the voltage values in the whole grid before the looping procedure for all the periods (peak, full, off-peak periods) are presented in Table A1 in the Appendix.

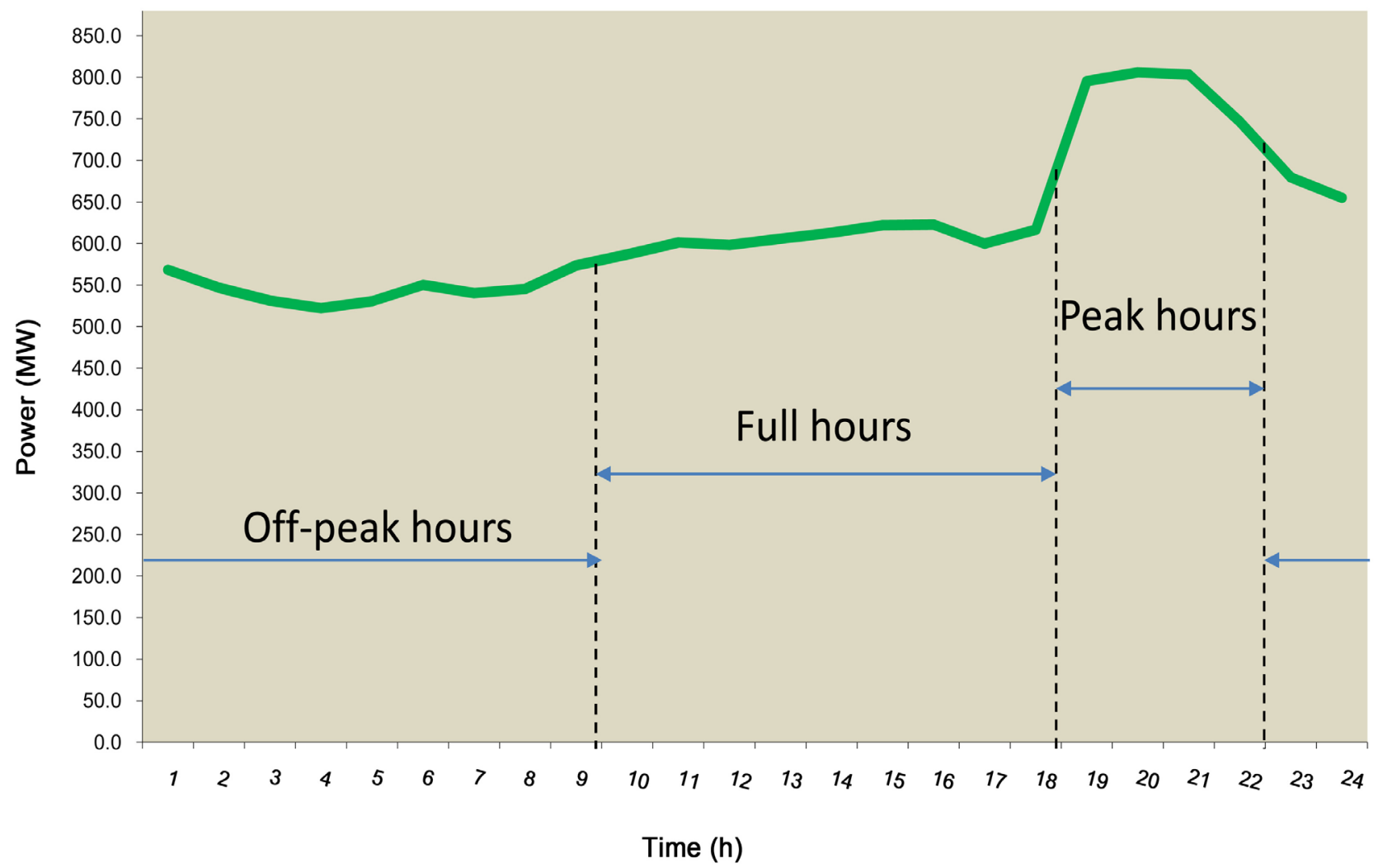

Figure 1. SIG load profile. 
Table 1. Nodes at which voltage values are unacceptable before the looping procedure.

\begin{tabular}{|c|c|c|c|c|c|c|}
\hline \multirow[b]{2}{*}{$\mathrm{N}^{\circ}$} & \multirow[b]{2}{*}{ Region } & \multirow[b]{2}{*}{ Bus bars } & \multirow{2}{*}{$\begin{array}{c}\text { Nominal } \\
\text { Voltage }\end{array}$} & \multicolumn{3}{|c|}{ Voltage drop $\Delta V(\%)$} \\
\hline & & & & $\begin{array}{c}\text { Peak } \\
\text { period }\end{array}$ & $\begin{array}{c}\text { Full } \\
\text { period }\end{array}$ & $\begin{array}{c}\text { Off-peak } \\
\text { period }\end{array}$ \\
\hline 18 & & NGOUSSO & 90 & 12.57 & 5.04 & 3.94 \\
\hline 19 & Centre & KONDENGUI & 90 & 13.42 & 5.72 & 4.48 \\
\hline 23 & & DIBAMBA & 90 & 11.87 & 11.24 & 10.97 \\
\hline 24 & $\begin{array}{l}\text { Littoral } \\
\text { (Coast) }\end{array}$ & KOUMASSI & 90 & 14.07 & 14.69 & 13.47 \\
\hline 25 & & NGODI-BAKOKO & 90 & 12.83 & 12.60 & 12.03 \\
\hline 35 & West & BAFOUSSAM & 90 & 15.60 & -0.19 & -0.94 \\
\hline 36 & & BAMENDA & 90 & 11.86 & 2.21 & 0.91 \\
\hline
\end{tabular}

\subsection{Choice of the Looping Nodes}

As presented in the methodology, the criteria evaluated here are transmission line lengths, voltage levels and substation availability.

- Western Region:

For the sake of discharge of the $225 / 90 \mathrm{kV}$ substation transformers, and because of the distance from the region relative to the swing generator, looping will be performed here in $225 \mathrm{kV}$. The Songloulou substation is chosen because being the swing bus, its voltage is held permanently; likewise, it remains available in case of loss of a transport facility, and the transmission line to be built is relatively short compared to other cases.

- Central Region:

In addition to a $225 \mathrm{kV}$ transmission line under construction in this region, a second looping is required to bring all voltages back into the acceptable range. The Ahala substation is chosen because its voltage is good, with a maximum voltage drop during the peak period of $6.07 \%$ (see Table 3). In addition, it remains powered in case of loss of a transport facility and the transmission line lengths are lower in this case.

- Coastal Region:

It is normally looped and will therefore be considered as such in the final simulations, while replacing the transformers of the Logbaba substation which are overloaded.

\subsection{Choice of the Looping Lines}

The proposed looping lines have as their point of origin a substation chosen in the previous step, and for the point of arrival a node with low voltage, as presented in Table 1. Thus, the selected transports facilities are the $225 \mathrm{kV}$ Songloulou-Bafoussam line with the installation of a 180 MVA $225 / 90 \mathrm{kV}$ transformer in Bafoussam, and the $90 \mathrm{kV}$ Ahala-Ngousso line (in addition to the $225 \mathrm{kV}$ Ebolowa-Ahala line under construction) because they offer better performances. 


\subsection{Simulation of the Final Scenario}

The final simulation takes into account all the transport facilities cited in the previous step, in addition to the installation of $2180 \mathrm{MVA}$ transformers at the Logbaba substation replacing those of $105 \mathrm{MVA}$. The detailed results obtained as well as the improvement of the voltage values are recorded in Table A2 in the Appendix. Some results are presented in Table 2. For example, it can be observed that for the node Ngousso, goes from a voltage drop of $12.57 \%$ (an unacceptable value) to a voltage drop of $0.07 \%$ (a very satisfactory value). The same assessment can be made for the Bafoussam node, where the voltage drop goes from $15.60 \%$ to $-5.24 \%$.

Overall, it can be observed that looping can significantly improve voltage levels in an electrical network, despite a few nodes experiencing a drop in voltage, though they still remain within the acceptable range.

In addition to improving the voltage plan, other improvements are identified after looping the SIG:

Table 3 shows the load percentages of transformers and lines respectively overloaded and congested before looping the network; it is clear that after looping, these structures are heavily discharged/decongested, which gives a significant increase in their performances. This table also shows that looping reduces power losses in a network, but also simplifies it through the elimination of several capacitor banks and thermal power plants.

- Impact of looping during the full period and during the off-peak period

Table A3 and Table A4 present the values of voltage drops during the off-peak periodand de full period respectively. Initially, as explained in Section

Table 2. Exerpt of the results obtained in terms of voltage drops during the peak period of the sig network before and after the looping process.

\begin{tabular}{|c|c|c|c|c|c|}
\hline \multirow{2}{*}{$\mathbf{N}^{\bullet}$} & \multirow{2}{*}{ Bus bars } & \multirow{2}{*}{$\begin{array}{c}\text { Nominal } \\
\text { voltage }\end{array}$} & \multicolumn{2}{|c|}{$\begin{array}{l}\Delta \mathrm{V} \text { during the peak } \\
\text { period (\%) }\end{array}$} & \multirow{2}{*}{$\begin{array}{c}\text { Relative } \\
\text { difference } \\
(\%)\end{array}$} \\
\hline & & & $\begin{array}{l}\text { Initial } \\
\text { value }\end{array}$ & Final value & \\
\hline 1 & SONGLOULOU & 225 & -6.00 & -6.00 & 0.00 \\
\hline 3 & NOMAYOS & 90 & 5.96 & -3.22 & 9.76 \\
\hline 4 & AHALA & 90 & 6.07 & -3.19 & 9.85 \\
\hline 5 & NSIMALEN & 90 & 6.10 & -2.79 & 9.47 \\
\hline 6 & NGOUSSO & 90 & 12.57 & 0.07 & 14.30 \\
\hline 7 & KONDENGUI & 90 & 13.42 & 0.81 & 14.57 \\
\hline 8 & DIBAMBA & 90 & 11.87 & -4.87 & 18.99 \\
\hline 9 & KOUMASSI & 90 & 14.07 & -5.30 & 22.54 \\
\hline 10 & BAFOUSSAM & 90 & 15.60 & -5.24 & 24.70 \\
\hline
\end{tabular}


Table 3. Other improvements observed after the looping process during the peak period.

\begin{tabular}{cccc}
\hline Peak period & Initial case & Final case & Performances (\%) \\
\hline Bekoko transformer (\%) & 93 & 62 & 33.33 \\
Oyomabang-Ngousso line (\%) & 130 & 81 & 37.69 \\
Mangombe-Dibamba line (\%) & 104 & 44 & 57.69 \\
Necessary Capacitor banks & 7 & 3 & 57.14 \\
Power losses (MW) & 59.88 & 48.85 & 18.42 \\
Limbe power plant (MW) & 44 & 12 & 72.73 \\
Bamenda power plant (MW) & 14 & 0 & 100 \\
Oyomabang power plant (MW) & 12 & 0 & 100 \\
\hline
\end{tabular}

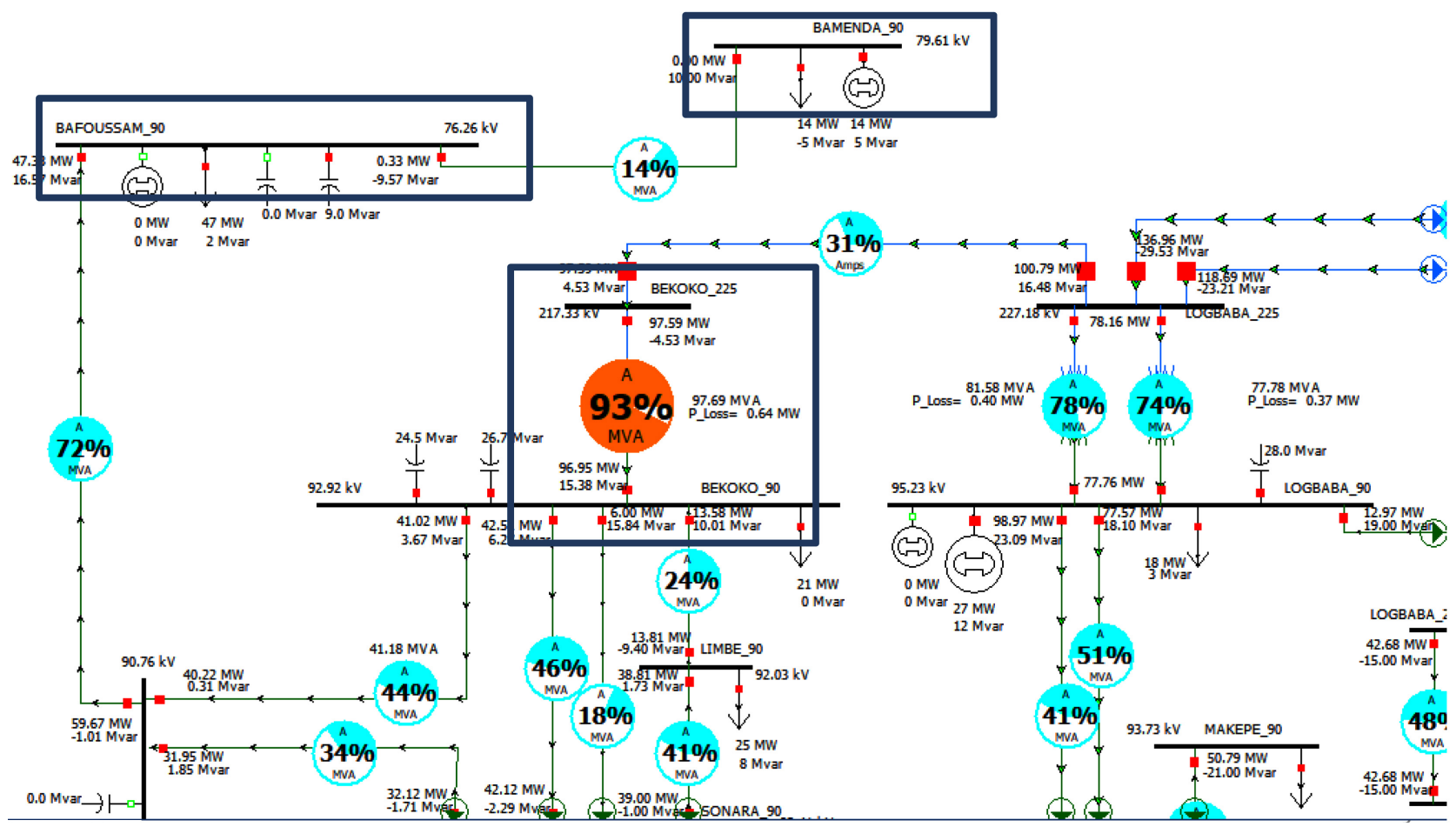

Figure 2. Overview of the Western SIG part of the network before the looping process.

4.1., the voltage drops were mostly acceptable in these periods before the looping of the grid. The values obtained after the looping process show that the looping does not create overvoltages during periods of low load, when the transformers regulate their secondary voltage. This suggests that it can be a good strategy to improve voltage quality in during period of high consumption, without deteriorating the voltage quality during the other periods.

Figure 2 presents the Western corridor of the SIG before the looping. It can be seen enormous power flows in the transmission lines, which leads to important voltage drops, power losses, transformer overload.

Figure 3 below presents that same corridor of the SIG after the looping. It can be seen important improvements especially concerned the voltage profile in the 


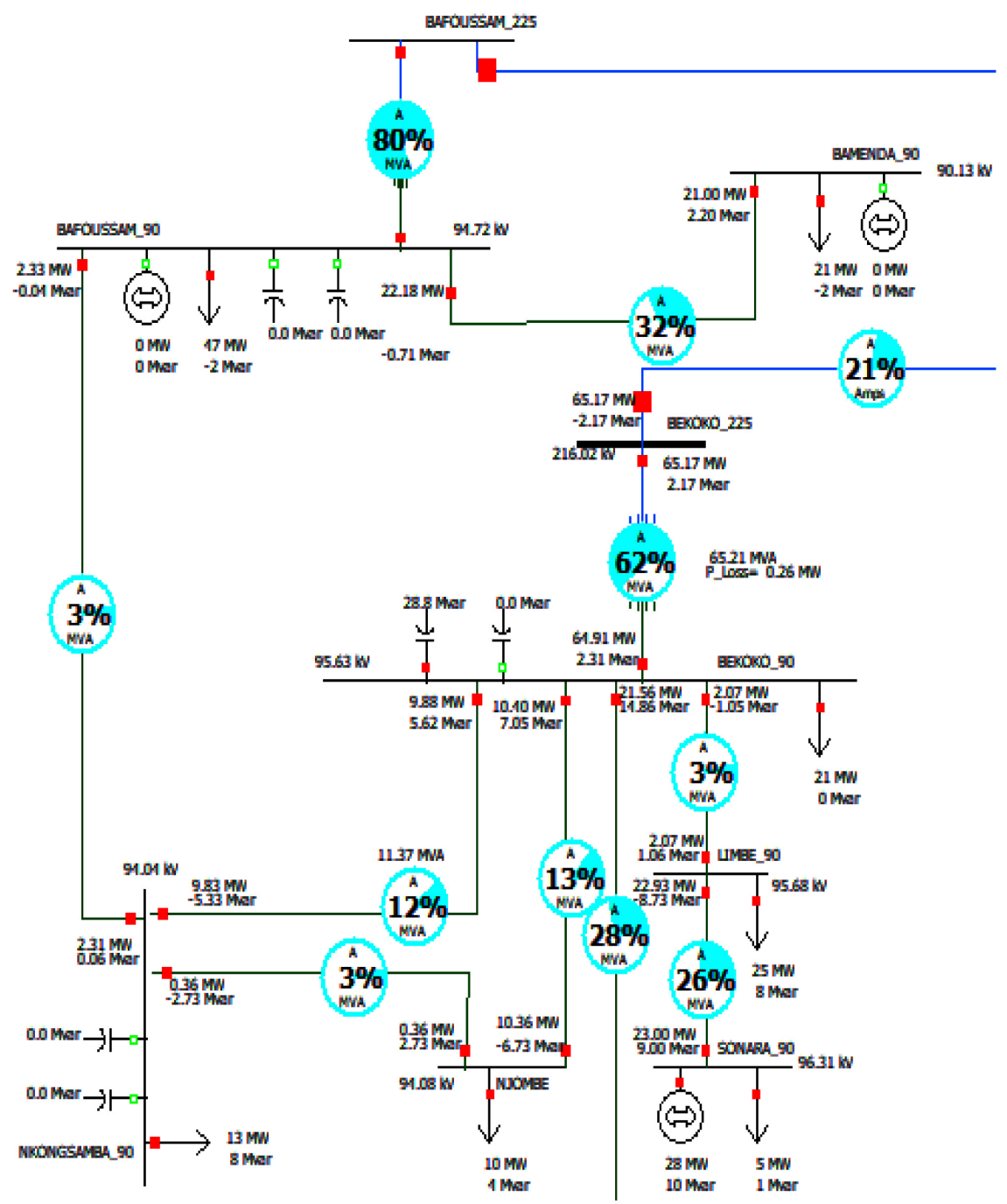

Figure 3. Overview of the Western SIG part of the network after the looping process.

region, the charge percentage of the Bekoko transformer, and the use of capacitor banks and Bamenda power plant.

\section{Conclusions}

In this study, the proposed method for improving voltage levels in an electrical network is looping. The procedure used takes into account the technical and economic aspects in order to determine the appropriate transmission lines for an optimal looping of the network. From the technical point of view, several improvements are observed in the final simulation. Looping can be said to improve the overall voltage plan of the network, by reducing all voltage drops in the acceptable range; it also allows the discharge of power transformers and a strong decongestion of the transmission lines, thus increasing the life service of this equipment. It offers a considerable reduction in power losses in the network, in addition to ensuring continuity of service in case of loss of a component of the transmission system. Finally, it allows the elimination of several capacitor banks, 
which makes it possible to eliminate the costs of maintenance and a removal of several local production sources.

For Cameroon in particular, the SIG looping allows an impressive optimization of network performances, i.e. $24.7 \%$ for the voltage at the Bafoussam substation, 37.69\% for the decongestion of the $90 \mathrm{kV}$ Oyomabang-Ngousso line, and $33.33 \%$ for the discharge of the Bekoko transformer. The power losses are reduced by $10 \mathrm{MW}$ averagely; four capacitor banks and 2 diesel thermal power plants are eliminated, which may lead in the long run, an optimization of the dispatch cost and thus a reduction of the cost of the electricity in Cameroon. In a general manner, the network offers flexibility in operations, a simplification, and an increase in its reliability.

\section{Conflicts of Interest}

The authors declare no conflicts of interest regarding the publication of this paper.

\section{References}

[1] Wang, X.F., Song, Y. and Irving, M. (2008) Modern Power Systems Analysis. Springer, Boston, MA. https://doi.org/10.1007/978-0-387-72853-7

[2] Moreno-Muños, A. (2007) Power Quality: Mitigation Technologies in a Distributed Environment. Springer, London. https://doi.org/10.1007/978-1-84628-772-5

[3] IEEE Recommended Practice for Monitoring Electric Power Quality. IEEE standards 1159-2009 (Revision of IEEE standards 1159-1995), 26 June 2009, 1-94.

[4] Bartak, G. (2004) Evaluation of Responses to the 2nd Questionnaire, Power Quality-Service Level Report No 2004-030-0703.

[5] IEC 61000-4-30 (2015) E.M.C.-Part 4. Testing and Measurement Techniques: Power Quality Measurement Methods, International Electrotechnical Commitee (IEC). http://www.iec.ch

[6] Razavi, S.-E., Rahimi, E., Javadi, M.S., Nezhad A.E., Lotfi, M., Shafie-Khah, M. and Catalão, J.P.S. (2019) Impact of Distributed Generation on Protection and Voltage Regulation of Distribution Systems: A Review. Renewable and Sustainable Energy Reviews, 105, 157-167. https://doi.org/10.1016/j.rser.2019.01.050

[7] Delfanti, M., Falabretti, D. and Merlo, M. (2013) Dispersed Generation Impact on Distribution Network Losses. Electric Power Systems Research, 97, 10-18. https://doi.org/10.1016/j.epsr.2012.11.018

[8] Firouz, O.D.Y., Farhadkhani, S., Lobry, J., Vallée, F. and Khakpour, A. (2014) Numerical Comparison of the Effects of Different Types of Distributed Generation Units on Overcurrent Protection Systems in MV Distribution Grids. Renewable Energy, 69, 271-283. https://doi.org/10.1016/j.renene.2014.03.035

[9] Xyngi, I. and Popov, M. (2013) An Intelligent Algorithm for the Protection of Smart Power Systems. IEEE Transactions on Smart Grid, 4, 1541-1548. https://doi.org/10.1109/TSG.2013.2244621

[10] Sharma, A., Rajpurohit, B.S. and Wang, L.F. (2016) D.G. Integration with Power Quality Improvement Feature for Smart Grid. In: Pant, M., Deep, K., Bansal, J., Nagar, A. and Das, K., Eds., Proceedings of Fifth International Conference on Soft 
Computing for Problem Solving, Springer, Singapore, 901-913.

https://doi.org/10.1007/978-981-10-0451-3_80

[11] Javadian, S.A.M., Haghifam, M.-R., Firoozabad, M.F., and Bathaee, S.M.T. (2013) Analysis of Protection System's Risk in Distribution Networks with DG. International Journal of Electrical Power \& Energy Systems, 44, 688-695. https://doi.org/10.1016/j.ijepes.2012.08.034

[12] Sithole, S., Mbuli, N. and Pretorius, J. (2013) Voltage Regulation in the Douglas Area Using Shunt Capacitor Banks and Controllable Shunt Reactors. 2013 13th International Conference on Environment and Electrical Engineering, Wroclaw, Poland, 1-3 November 2013, 85-90. https://doi.org/10.1109/EEEIC-2.2013.6737888

[13] Tirtashi, M.R.S., Samuelsson, O. and Svensson, J. (2013) Control Strategies for Reactive Shunts to Improve Long-Term Voltage Stability. 2013 48 th International Universities' Power Engineering Conference, Dublin, Ireland, 2-5 September 2013, 1-5. https://doi.org/10.1109/UPEC.2013.6715028

[14] Kundur, P. (1994) Power System Stability and Control. McGraw-Hill Education, New York..

[15] Faiz, J. and Siahkolah, B. (2003) New Solid-State Onload Tap-Changers Topology for Distribution Transformers. IEEE Transations on Power Delivery, 18, 136-141. https://doi.org/10.1109/TPWRD.2002.803723

[16] Zhang, X.-P. (2010) Fundamental of Electric Power Systems. Restructured Electric Power Systems: Analysis of Electricity Markets with Equilibrium Models. Wiley-IEEE Press. https://doi.org/10.1002/9780470608555

[17] Hingorani, N.G. and Gyugyi, L. (2000) FACTS Concept and General System Considerations. In: Hingorani, N.G. and Gyugyi, L. Eds., Understanding FACTS: Concepts and Technology of Flexible AC Transmission Systems, Wiley-IEEE Press, New York, 1-35.

[18] Khawaja, K., Khan, S., Lee, S.-J., Haider, Z., Rafique, M. and Kim, C.-H. (2018) A Real-Time Optimal Coordination Scheme for the Voltage Regulation of a Distribution Network Including an OLTC, Capacitor Banks, and Multiple Distributed Energy Resources. International Journal of Electrical Power \& Energy Systems, 94, 1-14. https://doi.org/10.1016/j.ijepes.2017.06.024

[19] Hand, M.M., et al. (2012) Renewable Electricity Futures Study. Volume 1. Exploration of High-Penetration Renewable Electricity Futures. Technical Report, the United States. https://doi.org/10.2172/1219711

[20] Sarimuthu, C.R., Ramachandaramurthy, V.K., Agileswari, K.R. and Mokhlis, H. (2016) A Review on Voltage Control Methods Using On-Load Tap Changer Transformers for Networks with Renewable Energy Sources. Renewable and Sustainable Energy Reviews, 62, 1154-1161. https://doi.org/10.1016/j.rser.2016.05.016

[21] Salih, S.N. and Chen, P. (2016) On Coordinated Control of OLTC and Reactive Power Compensation for Voltage Regulation in Distribution Systems with Wind Power. IEEE Transactions on Power Systems, 31, 4026-4035.

https://doi.org/10.1109/TPWRS.2015.2501433

[22] Gayatri, M.T.L., Parimi, A.M. and Kumar, A.V.P. (2018) A Review of Reactive Power Compensation Techniques in Microgrids. Renewable and Sustainable Energy Reviews, 81, 1030-1036. https://doi.org/10.1016/j.rser.2017.08.006

[23] Tina, G.M., Garozzo, D. and Siano, P. (2019) Scheduling of PV Inverter Reactive Power Set-Point and Battery Charge/Discharge Profile for Voltage Regulation in Low Voltage Networks. International Journal of Electrical Power \& Energy Systems, 107, 131-139. https://doi.org/10.1016/j.ijepes.2018.11.009 
[24] Iioka, D., Fujii, T., Tanaka, T., Harimoto, T. and Motoyama, J. (2020) Voltage Reduction in Medium Voltage Distribution Systems Using Constant Power Factor Control of PV PCS. Energies, 13, Article No. 5430.

https://doi.org/10.3390/en13205430

[25] Zimann, F.J., Batschauer, A.L., Mezaroba, M. and Neves, F.A.S. (2019) Energy Storage System Control Algorithm for Voltage Regulation with Active and Reactive Power Injection in Low-Voltage Distribution Network. Electric Power Systems Research, 174, Article No.105825. https://doi.org/10.1016/j.epsr.2019.04.003

[26] Overbye, T.J. (2004) Power System Simulation: Understanding Small- and LargeSystem Operations. IEEE Power and Energy Magasine, 2, 20-30. https://doi.org/10.1109/MPAE.2004.1263413

[27] EN 50160 (2010) Voltage Characteristics of Electricity Supplied by Public Distribution Networks, European Committee for Electrotechnical Standardization.

https://www.cenelec.eu/ 


\section{Appendix}

Table A1. Voltage drops at each node of the sig network before the looping process (base case).

\begin{tabular}{|c|c|c|c|c|c|}
\hline \multirow[b]{2}{*}{$\mathrm{N}^{\bullet}$} & \multirow[b]{2}{*}{ Bus bars } & \multirow{2}{*}{$\begin{array}{l}\text { Nominal } \\
\text { Voltage }\end{array}$} & \multicolumn{3}{|c|}{ Voltage drop $\Delta \mathrm{V}(\%)$} \\
\hline & & & $\begin{array}{c}\text { Peak } \\
\text { period }\end{array}$ & $\begin{array}{c}\text { Full } \\
\text { period }\end{array}$ & $\begin{array}{c}\text { Off-peak } \\
\text { period }\end{array}$ \\
\hline 1 & SONGLOULOU & 225 & -6.00 & -6.00 & -6.00 \\
\hline 2 & MEMVE'ELE & 225 & -4.00 & -4.00 & -4.00 \\
\hline 3 & KRIBI & 225 & -5.48 & -5.04 & -4.88 \\
\hline 4 & EBOLOWA_225 & 225 & -2.50 & -3.01 & -2.76 \\
\hline 5 & MANGOMBE_225 & 225 & -3.61 & -3.61 & -3.48 \\
\hline 6 & OYOMABANG_225 & 225 & 7.67 & 4.36 & 5.95 \\
\hline 7 & LOGBABA_225 & 225 & -0.95 & -0.93 & -0.76 \\
\hline 8 & BEKOKO_225 & 225 & 3.52 & -2.80 & 3.38 \\
\hline 9 & EBOLOWA_90 & 90 & -0.90 & -0.17 & -5.89 \\
\hline 10 & MANGOMBE_90 & 90 & -3.13 & -4.32 & -4.42 \\
\hline 11 & OYOMABANG_90 & 90 & 5.48 & 2.20 & -0.68 \\
\hline 12 & LOGBABA_90 & 90 & -5.78 & -4.22 & -4.80 \\
\hline 13 & BEKOKO_90 & 90 & -3.10 & -6.69 & -4.82 \\
\hline 14 & NOMAYOS & 90 & 5.96 & 2.84 & -0.33 \\
\hline 15 & AHALA & 90 & 6.07 & 3.01 & -0.26 \\
\hline 16 & MBALMAYO & 90 & 5.46 & 3.46 & -0.72 \\
\hline 17 & NSIMALEN & 90 & 6.10 & 3.29 & -0.22 \\
\hline 18 & NGOUSSO & 90 & 12.57 & 5.04 & 3.94 \\
\hline 19 & KONDENGUI & 90 & 13.42 & 5.72 & 4.48 \\
\hline 20 & BRGM & 90 & 5.78 & 2.54 & -0.51 \\
\hline 21 & NDJOCK-NKONG & 90 & 3.23 & 0.41 & -1.70 \\
\hline 22 & EDEA & 90 & -3.31 & -4.49 & -4.63 \\
\hline 23 & DIBAMBA & 90 & 11.87 & 11.24 & 10.97 \\
\hline 24 & KOUMASSI & 90 & 14.07 & 14.69 & 13.47 \\
\hline 25 & NGODI-BAKOKO & 90 & 12.83 & 12.60 & 12.03 \\
\hline 26 & MAKEPE & 90 & -4.10 & -2.49 & -3.36 \\
\hline 27 & BASSA & 90 & -4.90 & -3.21 & -4.07 \\
\hline 28 & DEIDO & 90 & -4.07 & -2.53 & -3.41 \\
\hline 29 & DANGOTE & 90 & -1.16 & -2.59 & -1.63 \\
\hline 30 & BONABERI & 90 & -1.73 & -5.07 & -2.67 \\
\hline 31 & SONARA & 90 & -2.52 & -8.40 & -2.80 \\
\hline 32 & LIMBE & 90 & -2.10 & -7.72 & -2.77 \\
\hline 33 & NJOMBE & 90 & -1.18 & -9.66 & -5.36 \\
\hline 34 & NKONGSAMBA & 90 & -0.66 & -9.50 & -5.16 \\
\hline 35 & BAFOUSSAM & 90 & 15.60 & -0.19 & -0.94 \\
\hline 36 & BAMENDA & 90 & 11.86 & 2.21 & 0.91 \\
\hline
\end{tabular}


Table A2. Voltage drops during the peak period of the sig network before and after the looping process.

\begin{tabular}{|c|c|c|c|c|c|}
\hline \multirow{2}{*}{$\mathrm{N}^{\circ}$} & \multirow{2}{*}{ Bus bars } & \multirow{2}{*}{$\begin{array}{l}\text { Nominal } \\
\text { Voltage }\end{array}$} & \multicolumn{2}{|c|}{$\begin{array}{c}\Delta \mathrm{V} \text { during the peak } \\
\text { period (\%) }\end{array}$} & \multirow{2}{*}{$\begin{array}{c}\text { Relative } \\
\text { difference (\%) }\end{array}$} \\
\hline & & & $\begin{array}{l}\text { Initial } \\
\text { value }\end{array}$ & $\begin{array}{l}\text { Final } \\
\text { value }\end{array}$ & \\
\hline 1 & SONGLOULOU & 225 & -6.00 & -6.00 & 0.00 \\
\hline 2 & MEMVE'ELE & 225 & -4.00 & -4.00 & 0.00 \\
\hline 3 & KRIBI & 225 & -5.48 & -5.00 & -0.46 \\
\hline 4 & EBOLOWA_225 & 225 & -2.50 & -2.65 & 0.15 \\
\hline 5 & MANGOMBE_225 & 225 & -3.61 & -3.64 & 0.02 \\
\hline 6 & OYOMABANG_225 & 225 & 7.67 & 4.36 & 3.58 \\
\hline 7 & LOGBABA_225 & 225 & -0.95 & 0.43 & -1.36 \\
\hline 8 & BEKOKO_225 & 225 & 3.52 & 3.99 & -0.49 \\
\hline 9 & EBOLOWA_90 & 90 & -0.90 & -2.46 & 1.54 \\
\hline 10 & MANGOMBE_90 & 90 & -3.13 & -6.00 & 2.78 \\
\hline 11 & OYOMABANG_90 & 90 & 5.48 & -3.39 & 9.38 \\
\hline 12 & LOGBABA_90 & 90 & -5.78 & -5.39 & -0.37 \\
\hline 13 & BEKOKO_90 & 90 & -3.10 & -6.26 & 3.06 \\
\hline 14 & NOMAYOS & 90 & 5.96 & -3.22 & 9.76 \\
\hline 15 & AHALA & 90 & 6.07 & -3.19 & 9.85 \\
\hline 16 & MBALMAYO & 90 & 5.46 & -2.21 & 8.11 \\
\hline 17 & NSIMALEN & 90 & 6.10 & -2.79 & 9.47 \\
\hline 18 & NGOUSSO & 90 & 12.57 & 0.07 & 14.30 \\
\hline 19 & KONDENGUI & 90 & 13.42 & 0.81 & 14.57 \\
\hline 20 & BRGM & 90 & 5.78 & -3.12 & 9.45 \\
\hline 21 & NDJOCK-NKONG & 90 & 3.23 & -2.58 & 6.01 \\
\hline 22 & EDEA & 90 & -3.31 & -6.00 & 2.60 \\
\hline 23 & DIBAMBA & 90 & 11.87 & -4.87 & 18.99 \\
\hline 24 & KOUMASSI & 90 & 14.07 & -5.30 & 22.54 \\
\hline 25 & NGODI-BAKOKO & 90 & 12.83 & -4.86 & 20.29 \\
\hline 26 & MAKEPE & 90 & -4.10 & -3.80 & -0.29 \\
\hline 27 & BASSA & 90 & -4.90 & -4.60 & -0.29 \\
\hline 28 & DEIDO & 90 & -4.07 & -4.06 & -0.01 \\
\hline 29 & DANGOTE & 90 & -1.16 & -2.92 & 1.75 \\
\hline 30 & BONABERI & 90 & -1.73 & -4.70 & 2.92 \\
\hline 31 & SONARA & 90 & -2.52 & -7.01 & 4.38 \\
\hline 32 & LIMBE & 90 & -2.10 & -6.31 & 4.12 \\
\hline 33 & NJOMBE & 90 & -1.18 & -4.53 & 3.32 \\
\hline 34 & NKONGSAMBA & 90 & -0.66 & -4.49 & 3.81 \\
\hline 35 & BAFOUSSAM & 90 & 15.60 & -5.24 & 24.70 \\
\hline 36 & BAMENDA & 90 & 11.86 & -0.14 & 13.61 \\
\hline
\end{tabular}


Table A3. Voltage drops during the full period.

\begin{tabular}{|c|c|c|c|c|}
\hline \multirow{2}{*}{$\mathbf{N}^{\bullet}$} & \multirow{2}{*}{ Bus bars } & \multirow{2}{*}{$\begin{array}{l}\text { Nominal } \\
\text { Voltage }\end{array}$} & \multicolumn{2}{|c|}{$\begin{array}{l}\Delta \mathrm{V} \text { during the full } \\
\text { period (\%) }\end{array}$} \\
\hline & & & Initial value & $\begin{array}{l}\text { Final } \\
\text { value }\end{array}$ \\
\hline 1 & SONGLOULOU & 225 & -6.00 & -6.00 \\
\hline 2 & MEMVE'ELE & 225 & -4.00 & -4.00 \\
\hline 3 & KRIBI & 225 & -5.04 & -4.95 \\
\hline 4 & EBOLOWA_225 & 225 & -3.01 & -4.64 \\
\hline 5 & MANGOMBE_225 & 225 & -3.61 & -3.52 \\
\hline 6 & OYOMABANG_225 & 225 & 4.36 & 1.13 \\
\hline 7 & LOGBABA_225 & 225 & -0.93 & 1.61 \\
\hline 8 & BEKOKO_225 & 225 & -2.80 & 2.96 \\
\hline 9 & EBOLOWA_90 & 90 & -0.17 & -2.34 \\
\hline 10 & MANGOMBE_90 & 90 & -4.32 & -5.99 \\
\hline 11 & OYOMABANG_90 & 90 & 2.20 & -2.39 \\
\hline 12 & LOGBABA_90 & 90 & -4.22 & -1.88 \\
\hline 13 & BEKOKO_90 & 90 & -6.69 & -2.76 \\
\hline 14 & NOMAYOS & 90 & 2.84 & -1.99 \\
\hline 15 & AHALA & 90 & 3.01 & -1.90 \\
\hline 16 & MBALMAYO & 90 & 3.46 & -1.28 \\
\hline 17 & NSIMALEN & 90 & 3.29 & -1.60 \\
\hline 18 & NGOUSSO & 90 & 5.04 & -0.93 \\
\hline 19 & KONDENGUI & 90 & 5.72 & -0.30 \\
\hline 20 & BRGM & 90 & 2.54 & -2.06 \\
\hline 21 & NDJOCK-NKONG & 90 & 0.41 & -2.70 \\
\hline 22 & EDEA & 90 & -4.49 & -6.00 \\
\hline 23 & DIBAMBA & 90 & 11.24 & -2.04 \\
\hline 24 & KOUMASSI & 90 & 14.69 & -1.72 \\
\hline 25 & NGODI-BAKOKO & 90 & 12.60 & -1.80 \\
\hline 26 & MAKEPE & 90 & -2.49 & -0.13 \\
\hline 27 & BASSA & 90 & -3.21 & -0.88 \\
\hline 28 & DEIDO & 90 & -2.53 & -0.28 \\
\hline 29 & DANGOTE & 90 & -2.59 & -0.04 \\
\hline 30 & BONABERI & 90 & -5.07 & -1.41 \\
\hline 31 & SONARA & 90 & -8.40 & -2.01 \\
\hline 32 & LIMBE & 90 & -7.72 & -1.68 \\
\hline 33 & NJOMBE & 90 & -9.66 & -2.18 \\
\hline 34 & NKONGSAMBA & 90 & -9.50 & -2.28 \\
\hline 35 & BAFOUSSAM & 90 & -0.19 & -4.93 \\
\hline 36 & BAMENDA & 90 & 2.21 & -1.39 \\
\hline
\end{tabular}


Table A4. Voltage drops during the off-peak period.

\begin{tabular}{|c|c|c|c|c|}
\hline \multirow[t]{2}{*}{$\mathrm{N}^{\bullet}$} & \multirow[t]{2}{*}{ Bus bars } & \multirow{2}{*}{$\begin{array}{l}\text { Nominal } \\
\text { Voltage }\end{array}$} & \multicolumn{2}{|c|}{$\begin{array}{l}\Delta V \text { During the } \\
\text { full period (\%) }\end{array}$} \\
\hline & & & Initial value & Final value \\
\hline 1 & SONGLOULOU & 225 & -6.00 & -6.00 \\
\hline 2 & MEMVE'ELE & 225 & -4.00 & -4.00 \\
\hline 3 & KRIBI & 225 & -4.88 & -4.70 \\
\hline 4 & EBOLOWA_225 & 225 & -2.76 & -4.50 \\
\hline 5 & MANGOMBE_225 & 225 & -3.48 & -3.73 \\
\hline 6 & OYOMABANG_225 & 225 & 5.95 & 3.50 \\
\hline 7 & LOGBABA_225 & 225 & -0.76 & -0.49 \\
\hline 8 & BEKOKO_225 & 225 & 3.38 & 1.79 \\
\hline 9 & EBOLOWA_90 & 90 & -5.89 & -7.94 \\
\hline 10 & MANGOMBE_90 & 90 & -4.42 & -6.00 \\
\hline 11 & OYOMABANG_90 & 90 & -0.68 & -4.13 \\
\hline 12 & LOGBABA_90 & 90 & -4.80 & -2.89 \\
\hline 13 & BEKOKO_90 & 90 & -4.82 & -3.13 \\
\hline 14 & NOMAYOS & 90 & -0.33 & -3.66 \\
\hline 15 & AHALA & 90 & -0.26 & -3.54 \\
\hline 16 & MBALMAYO & 90 & -0.72 & -4.12 \\
\hline 17 & NSIMALEN & 90 & -0.22 & -3.57 \\
\hline 18 & NGOUSSO & 90 & 3.94 & -1.40 \\
\hline 19 & KONDENGUI & 90 & 4.48 & -0.89 \\
\hline 20 & BRGM & 90 & -0.51 & -3.97 \\
\hline 21 & NDJOCK-NKONG & 90 & -1.70 & -4.11 \\
\hline 22 & EDEA & 90 & -4.63 & -6.00 \\
\hline 23 & DIBAMBA & 90 & 10.97 & -2.87 \\
\hline 24 & KOUMASSI & 90 & 13.47 & -2.78 \\
\hline 25 & NGODI-BAKOKO & 90 & 12.03 & -2.67 \\
\hline 26 & MAKEPE & 90 & -3.36 & -1.47 \\
\hline 27 & BASSA & 90 & -4.07 & -2.19 \\
\hline 28 & DEIDO & 90 & -3.41 & -1.67 \\
\hline 29 & DANGOTE & 90 & -1.63 & -0.23 \\
\hline 30 & BONABERI & 90 & -2.67 & -1.06 \\
\hline 31 & SONARA & 90 & -2.80 & -1.64 \\
\hline 32 & LIMBE & 90 & -2.77 & -1.50 \\
\hline 33 & NJOMBE & 90 & -5.36 & -2.99 \\
\hline 34 & NKONGSAMBA & 90 & -5.16 & -3.07 \\
\hline 35 & BAFOUSSAM & 90 & -0.94 & -6.58 \\
\hline 36 & BAMENDA & 90 & 0.91 & -4.70 \\
\hline
\end{tabular}

